\title{
СПОСОБЫ КОНТРОЛЯ В ПРОЦЕССЕ РАЦИОНАЛИЗАЦИИ ПОДГОТОВКИ БУДУЩЕГО ПРЕПОДАВАТЕЛЯ ИНОСТРАННЫХ ЯЗЫКОВ И КУЛЬТУР НОВОЙ ФОРМАЦИИ
}

\section{WAYS OF CONTROL IN RATIONALISATION OF TRAINING OF THE FUTURE TEACHER OF FOREIGN LANGUAGES AND CULTURE OF A NEW FORMATION}

\section{R. Managarov}

E. Milovanova

Summary: The article is devoted to a question of preparation of the future teachers of a foreign language and culture in conditions of modern school. The main attention is paid to actual ways of control in the training process of the future teacher of a new formation. These ways reorient the teaching process from theory to practice.

Keywords: teacher of foreign languages and cultures of a new formation; ways of control; forms of control; rationalization of the training process; functions of teachers of a new formation; contemporary education.
B современных условиях развития образования в области неродных языков требования к преподавателю меняются. Современный преподаватель иностранного языка - это личность, способная и готовая осуществлять широкий спектр профессиональных компетенций: от социальной до креативной. Рассмотрим отличительные особенности, которые, с нашей точки зрения, характеризуют традиционного учителя иностранного языка и преподавателя иностранных языков и культур новой формации.

Традиционный учитель. Функции:

- организация класса;

- управление вниманием посредством контроля;

- предъявление материала в форме «Я-говорю преподавание» и строгое наблюдение за выполнением заданий;

- осуществление контроля, «наказание» за невыполнение задания, упражнения (оценкой, например);

- следование тематике учебника и материалу программы, отсутствие стремления «расширить» контекст рассматриваемого вопроса;

- обучение в формате «натаскивание к ОГЭ/ЕГЭ»;

- владение главным образом одним иностранным языком на уверенном уровне.

\author{
Манагаров Роман Викторович \\ К.п.н., дочент, ГБОУ ВО «Ставропольский \\ государственный педагогический \\ институт» филиал в г. Буденновске \\ managarov.roman@yandex.ru \\ Милованова Елена Сергеевна \\ К.n.н., дочент, ГБОУ ВО «Ставропольский \\ государственный педагогический \\ институт» филиал в г. Буденновске \\ mes-7272@mail.ru
}

Аннотация: Статья посвящена подготовке будущих преподавателей иностранного языка и культуры новой формации в условиях современной школы. Особое внимание уделяется формам и способам осуществления контроля в процессе подготовки преподавателей новой формации. Данные способы направлены на переориентировку обучения с теории на практику.

Ключевые слова: преподаватель иностранных языков и культур новой формации; способы контроля; формы контроля; рационализация процесса обучения; функции преподавателя новой формации; современное обучение.

Функции преподавателя иностранных языков и культур новой формации в данной связи представляются несколько иными:

- управление классом/аудиторией/группой, грамотная реализация технологии современного педагогического менеджмента;

- организация познавательной деятельности обучающихся и управление их вниманием посредством заинтересованности изучающих иностранный язык овладевать новыми компетенциями;

- преобразование модели «Я-говорю преподавание» в модель «Мы-говорим преподавание» [1], которая предполагает интерактивные, активные, коммуникативные формы работы на занятиях;

- упор в обучении на задания когнитивного и практического/проблемного характера;

- реализация модели «от строгого контроля за успеваемостью» к самоконтролю и самооцениванию обучающихся [4: с. 102];

- стремление расширить контекст рассматриваемой темы посредством привлечения иных материалов, доводов, аргументов, приемов наглядности и пр.;

- уход от обучения в формате «дрилль», механических «зазубриваний правильных ответов», переход на практический характер обучения с учетом требований ЕГЭ/ОГЭ; 
- владение не одним, а несколькими иностранными языками, что особенно актуально в современном глобализированном мире, и в сфере преподавания в том числе, учитывая дефицит квалифицированных кадров данной сферы.

Концепция будущего преподавателя иностранных языков и культур новой формации предполагает подготовку современной, мобильной и лабильной личности, которая будет способна и готова работать по-новому в новых условиях образования [3: с.152]

В данной связи целесообразно говорить о смене парадигмы подготовки будущего преподавателя иностранных языков и культур новой формации. Традиционная парадигма подготовки учителя иностранного языка трансформируется в парадигму подготовки преподавателя иностранных языков и культур новой формации с соответствующим набором функций [6: с.114-117].

Современный преподаватель иностранных языков и культур новой формации - это компетентный, в высокой степени мотивированный педагог [2: с. 180], который должен получать качественную подготовку в различных областях научного знания, прежде всего, в иностранных языках, лингвистической, педагогической, психологической, и методической науках.

Соответственно меняются и требования к контролю уровня обученности студентов-будущих преподавателей. Говоря о видах контроля, которые в педагогике представлены предварительным, текущим, тематическим, итоговым [5], важно отметить необходимость ухода от формальности в процессе оценивания уровня сформированности компетенций обучающихся.

Одним из самых, наверное, распространенных способов осуществления любого контроля являются тестирование и традиционный опрос. Однако в последнее время также к этим способам добавились анализ проблемных ситуаций и периодически проекты, в отдельных случаях - мини-проекты.

В то же время, традиционный опрос и тесты остаются весьма «популярным» способом оценки знаний студенTOB.

Как нам представляется, такой подход необходимо пересмотреть в пользу когнитивных, практических, проблемных форм работы. Приведем отдельные примеры осуществления контроля на занятиях.

Вид контроля - текущий, применяется в ходе занятия. Тема лекционного занятия: «Принципы обучения в методической науке». Формы контроля: индивидуальный, групповой, фронтальный. Способ осуществления: интерактивный.

После того, как преподаватель предлагает вниманию студентов ряд определений принципов обучения различных исследователей (И.Л. Бим, М.В. Ляховицкий, Р.П. Мильруд, И.П. Подласый, С.Ф. Шатилов и др.), следующим действием для закрепления информации студентами и одновременно проверкой усвоенности материала может стать следующее задание: на слайде выводятся определения принципов обучения без указания фамилий авторов. Студенты без подсказок должны определить, кто является автором указанных определений. Кроме того, можно предложить ложную/некорректную информацию наряду с верными тезисами с целью определить, насколько студенты были внимательны при ознакомлении с новым материалом. Задача студентов в данной связи - определить ошибочное утверждение/ ложный тезис. Таким образом, каждую порцию информации теоретического характера можно сопровождать заданиями на усвоение/восприятие материала.

Рассмотрим следующий вид контроля - тематический, применяется после рассмотрения темы. Тема: «Современные технологии обучения иностранному языку и культуре. Технология контекстного обучения». Способ осуществления: моделирование педагогических ситуаций. Студентам, работающим в группах, целесообразно предложить следующие задания:

1. разработайте и презентуйте собственный кейс для урока иностранного языка в 5-11 классах с учетом тех требований, которые были рассмотрены в лекции;

2. интеллектуальная викторина по пройденной теме (студентам предлагаются вопросы по материалам лекций в формате «брейн-ринга»);

3. разработайте фрагмент урока с использованием современных технологий и продемонстрируйте свои умения в обучении потенциальных учеников видам речевой деятельности и аспектам языка.

Рассмотрим также итоговый вид контроля, который может применяться на зачетных занятиях. Один из способов осуществления: групповая дискуссия. В данном случае преподаватель предлагает целый ряд тем для обсуждения студентам. Студенты выбирают, например, три темы. Каждая тема рассматривается в отдельности. Темы носят проблемный, дискуссионный характер. Например: Какие методы обучения целесообразно использовать с точки зрения современного обучающего процесса, и какие методы кажутся вам неприемлемыми? Обоснуйте вашу точку зрения. Студенты соответственно должны продемонстрировать уровень знаний по дисциплине 
и умения вести дискуссию, дополнять высказывания, оспаривать позиции собеседников в отдельных случаях, отстаивать свое мнение и т. д.

Еще одним способом реализации итогового контроля может быть интеллектуальная викторина. Аудитория разделяется на 2-3 команды (каждая команда выбирает капитана, лидера, который регулирует и направляет ход обсуждения в группе). Аудитории предлагается ряд вопросов проблемного, практического характера, затрагивающих все темы курса. Каждый студент должен при- нимать участие в обсуждении, отстаивать свое мнение, доказывать правильность своих суждений. Преподаватель, в свою очередь, оценивает работу каждого студента, его вклад в общий «результат» группы/команды. В случае неудовлетворительной работы такой студент может получить дополнительный вопрос/проблемное задание/ситуацию. В качестве оценки деятельности студентов группы привлекаются «капитаны» команд, которые также оценивают степень вовлеченности каждого участника своей команды в процесс обсуждения вопросов/заданий, а также уровень продемонстрированных знаний.

\section{ЛИТЕРАТУРА}

1. Гальскова Н.Д. Гез Н.И. Теория обучения иностранным языкам: лингводидактика и методика: Учеб.пособие для студ.лингв.ун-тов и фак.ин.яз.высш.пед. учеб.заведений. - М.:Академия,2005. - 336 с.

2. Манагаров Р.В. 0 рационализации процесса обучения иностранному языку в современной школе // Сборник статей по материалам международного научно-методического симпозиума «Лемпертовские чтения - XVI»». Пятигорск: изд-во ПГЛУ, 2015. - C.178-181.

3. Манагаров Р.В., Красножонова Е.С. Рационализация процесса подготовки будущего учителя иностранного языка и культуры новой формации // Современные исследования социальных проблем (электронный научный журнал). - 2016. - №3-2. - С. 151-158.

4. Манагаров Р.В. Самооценивание обучающихся в процессе овладения иноязычными компетенциями // Сборник статей по материалам международного научно-методического симпозиума «Лемпертовские чтения - XVIII». Пятигорск, 2016. - С. 101-104.

5. Сластенин В.А., Исаев И.Ф., Шиянов Е.Н. Педагогика:Учеб. пособие для студ. высш. пед. учеб. заведений. - М.: Академия, 2012. - 608 с.

6. Krasnozhonova E.S., Managarov R.V. Functions of teacher of foreign language in conditions of modern development of educational process // The Third International Congress On Social Sciences and Humanities Proceedings of the Congress. Vienna, 2014. - C. 114-121.

\section{(c) Манагаров Роман Викторович (managarov.roman@yandex.ru), Милованова Елена Сергеевна (mes-7272@mail.ru)}

Журнал «Современная наука: актуальные проблемы теории и практики»

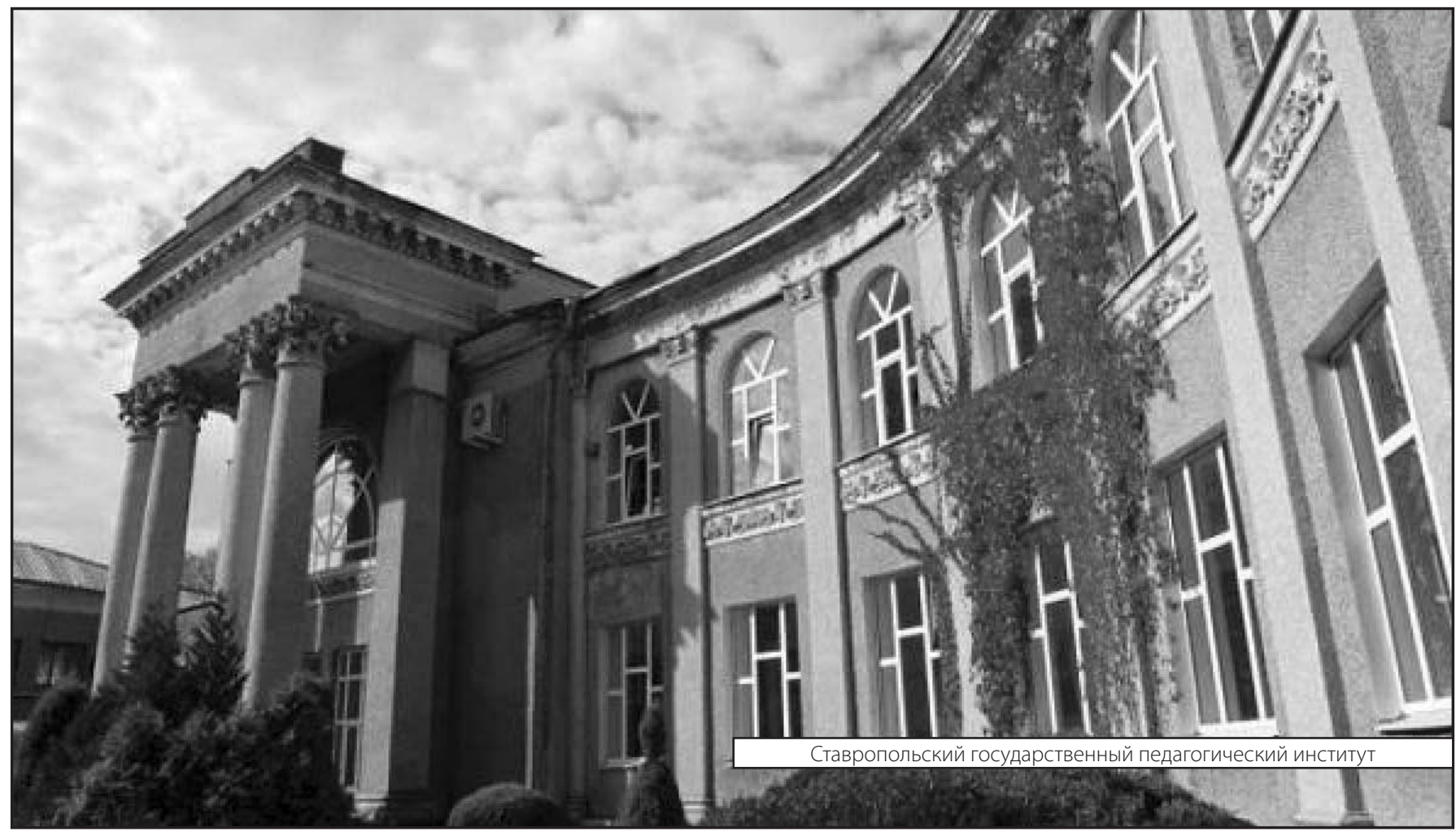

